\title{
PENGEMBANGAN MATA AIR CIBURIAL DI KAWASAN AGROWISATA GUNUNG MAS MENJADI WELLNESS TOURISM
}

\author{
Sri Pujiastuti, Sugiarto, \& Hengki Hermantoro \\ Sekolah Tinggi Pariwisata Trisakti \\ Email: cicihabibi29@gmail.com
}

How to cite (in APA Style): Pujiastuti, S., Sugiarto, \& Hermantoro, H. (2018). Pengembangan mata air ciburial di kawasan agrowisata gunung mas menjadi wellness tourism. Barista: Jurnal Kajian Bahasa dan Pariwisata, 5(2), Desember 2018, 203-214.

\begin{abstract}
Abstrak: Wisata kebugaran atau wellness tourism, merupakan salah satu wisata yang saat ini sudah menjadi tren. PT. Perkebunan VIII adalah agrowisata Gunung Mas yang mempunyai potensi untuk dikembangkan menjadi wisata kebugaran. Penelitian ini bertujuan untuk mengetahui penyebab rendahnya kunjungan wisatawan yang datang ke Gunung Mas dan untuk mengetahui faktor internal dan external. Desain yang digunakan adalah kualitatif dengan metode probality sampling. Informan yang digunakan sebanyak 30 informan. Analisis data yang digunakan adalah matriks IE dan Matriks SWOT. Dan hasil dari analisa SWOT. Dengan potensi untuk dikembangkan yaitu Mata air Ciburial dan atraksi paralayang sebagai faktor strenght dan weakness dan fasilitas yang dikembangkan dan dibantu oleh stake holder dengan tujuan menghasilkan peluang lapangan pekerjaan karena munculnya potensi bisnis sekitar Gunung Mas. Dari hasil wawancara dan observasi maka dapat disimpulkan bahwa, Gunung Mas berpotensi menjadi wisata kebugaran, maka tren wisata berubah dari mass tourism menjadi wisata dengan minat khusus.
\end{abstract}

Kata kunci: Agrowisata, wisata kebugaran, Matrik SWOT

\section{THE DEVELOPMENT OF CIBURIAL SPRINGS IN GUNUNG MAS AGRO-TOURISM AREAS TO BE WELLNESS TOURISM}

\begin{abstract}
Fitness tourism or wellness tourism is one of the most of the tourism that has become a trend. PT. Perkebunan VIII, espesially Agrowisata Gunung Mas is has potential to be developed into a wellnest tourism., This study aims to determine the causes of low tourist arrivals coming to Gunung Mas and to know the internal and external factors. The design of Methodology used is qualitative with probability sampling method. Informants used as many as 30 informants. The data analysis used is IE matrix and SWOT matrix. And the result of SWOT analysis. The potential area to be developed is Mata Air Ciburial and paralayang attractions as a factor of strength and weakness and facilities developed and will be coorborate by stakeholders with the aim of generating job opportunities due to the emergence of business potential around Gunung Mas. From the results of interviews and observations it can be concluded that, Gunung Mas has the potential to become a wellnest tourism, then the tourist trends changed from mass tourism to tourism with special interest.
\end{abstract}

Keywords: Agro Tourism, Fitness Tour, SWOT Matrix 


\section{PENDAHULUAN}

Perkembangan pariwisata di Indonesia terlihat cukup pesat saat ini, pariwisata merupakan suatu sektor yang sangat penting dan memiliki pengaruh yang cukup nyata dalam pengembangan ekonomi negara. Maka program pengembangan dan pendayagunaan sumber daya dan potensi pariwisata daerah diharapkan dapat memberikan sumbangan pembangunan ekonomi

Agrowisata kebun teh dapat dijadikan "wisata kebugaran" dengan mengembangkan mata air Ciburial dimana produk utamanya adalah teh sebagai komoditi spa, dan mata air Ciburial yang akan digunakan untuk lokasi SPA dan membuatkan paket wisata kebugaran dengan memperdayakan masyarakat sekitar dan fasilitas yang ada.

Wisata kebugaran saat ini sudah menjadi lifestyle dan menurut Global Wellness Economy, memprediksi bahwa pada tahun 2015, wellness lifestyle akan mencapai market sekitar \$118.8 triliun dimana akan berkonsentrasi pada America Utara, Asia, dan Eropa.

Dengan begitu maka dapat ditarik kesimpulan indentifikasi masalahnya adalah sebagai berikut:

1. Apakah penyebab rendahnya kunjungan wisatawan yang berkunjung di Perkebunan Gunung Mas PTPN VIII?

2. Elemen apakah yang terdapat dalam Wellness Tourism?

3. Bagaimanakah Strategi SWOT yang dapat dilakukan Perkebunan Gunung Mas PTPN VIII untuk menarik wisatawan?

Beberapa manfaat wisata agro meliputi: Meningkatkan Konservasi Lingkungan, Meningkatkan Nilai Estetika dan Keindahan Alam, Memberikan Nilai Rekreasi, Kegiatan Ilmiah dan Pengembangan Ilmu Pengetahuan, Tirtawinata (1999). Terdapat terdapat 4 (empat) komponen yang harus dimiliki oleh sebuah daya tarik wisata yaitu : (1) pertama, atraksi (attractions), seperti alam yang menarik, kebudayaan daerah yang menawan dan seni pertunjukkan;(2) kedua, aksesibiltas (accessibilities), seperti transportasi lokal dan adanya terminal; (3) ketiga, amenitas seperti tersedianya akomodasi, rumah makan, dan agen perjalanan; (4) keempat, ancillary service yaitu organisasi kepariwisataan yang dibutuhkan untuk pelayanan wisatawan seperti organisasi manajemen pemasaran wisata Cooper (2015)

Wellness dapat digambarkan sebagai sebuah proses di mana individu membuat pilihan dan terlibat dalam kegiatan dengan cara mempromosikan mengarahkan gaya hidup yang sehat, yang pada gilirannya berdampak positif bagi kesehatan individu itu sendiri Barre,2005. mendefinisikan wellness sebagai bagian khusus dalam kesehatan yang memandang kesehatan dari keseluruhan pandangan mengenai wellbeing, yang membagi manusia menjadi jiwa, raga dan pikiran dan saling bergantung dengan lingkungannya Dunn (1959) dalam koncul (2012:527)

Kesepuluh elemen itu adalah air (water), nourishment (nutrisi), movement (gerakan), integration (integrasi), aesthetic (seni), environment (lingkungan), cultural expression (ekspresi budaya), social contribution (kontribusi sosial), dan time and space rhythms ( ritme waktu dan ruang) http://www.ispaconference.com.

Perawatan spa terdiri dari creambath, facial, manicure-pedicure, lulur, scrub, foot spa dan body treatment dan juga ada beberapa tempat yang memakai konsep aromaterapi, Cooksley,1996:3.4) 


\section{METODE}

Jenis penelitian dalam penelitian ini adalah penelitian kualitatif dan jenis data yang digunakan adalah data sekunder, dan peneliti mengambil sampel menggunakan non probability sampling, terutama Judgment Sampling, dan teknik data menggunakan observasi, wawancara dan dokumentasi dengan informan total 30 orang. Jenis penelitian terdiri dari data sekunder adalah koleksi dari informan dengan wawancara, observasi dan dokumentasi. Total informan yaitu 30 orang.

\section{HASIL DAN PEMBAHASAN}

Berdasarkan hasil wawancara, pengamatan langsung ke pengunjung dapat diperoleh data sebagai berikut.

\section{- Atraksi}

Paralayang merupakan salah satu atraksi wisata dan area pendaratan paralayang menjadi salah satu daya tarik yang bisa dinikmati pengunjung dan juga menikmati pemandangan indah pegunungan hijau teh dengan air dingin berasal dari tanah. Daya tarik wisata ini sesuai dengan teori tarikmenarik berdasarkan Cooper (2000), Attraction atau atraksi merupakan produk utama sebuah tujuan. Atraksi terkait dengan apa yang harus dilihat dan apa yang harus dilakukan. Apa yang bisa dilihat dan dilakukan wisatawan di destinasi tersebut. Atraksi bisa menjadi keindahan dan keunikan alam, budaya masyarakat setempat, peninggalan bangunan bersejarah, serta atraksi buatan seperti fasilitas permainan dan hiburan.
Berdasarkan teori tersebut, Daya tarik merupakan objek wisata dimana ada sesuatu yang unik untuk menarik perhatian pengunjung.

Aksesibilitas

Dengan teori yang sama bahwa Cooper (2000), menurut akses Cooper seperti transportasi lokal dan terminal, berdasarkan pengamatan, lokasi mata air Ciburial yang terletak di Tugu selatan, dapat dicapai dengan transportasi umum dengan tujuan Bogor Cisarua atau juga dapat gunakan mini cab dengan tujuan Bogor - Cipanas, dan dengan bus dengan rute Bogor - Bandung. Bisa ditempuh juga dengan menggunakan mobil, motor dan kendaraan

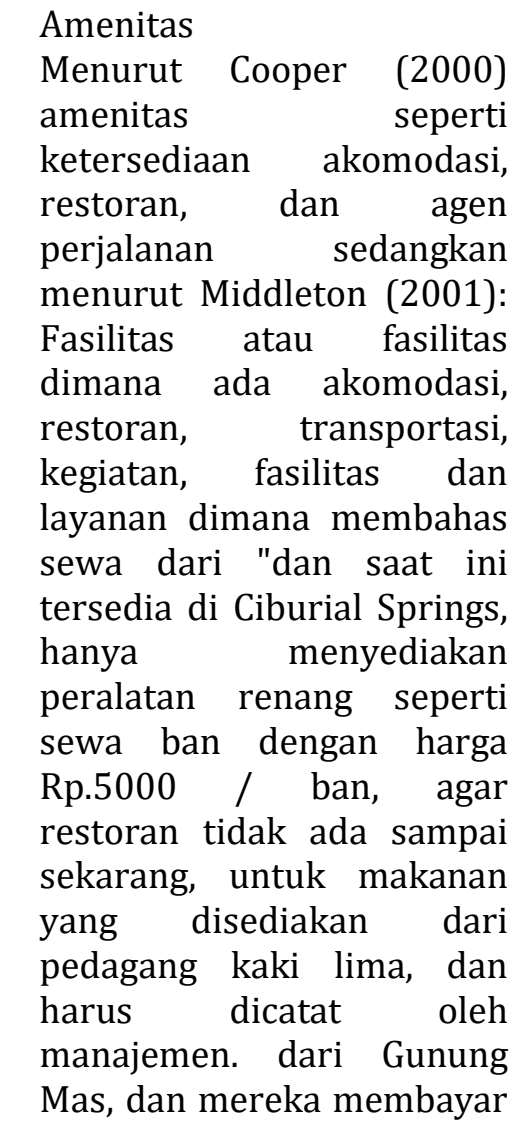


sewa $\mathrm{Rp} 15.000$ per bulan, Ciburial Spring memiliki fasilitas seperti 5 gazebos, 2 kanopi, 2 toilet multi fungsi untuk pembilasan setelah berenang, dan ada 4 sampah dengan ukuran yang cukup besar, dan menyediakan lantai sewaan. tikar seharga Rp 15.000, Mushola yang berada di dekat mata air Ciburial dan area parkir terbagi menjadi 3 lokasi yaitu, titik pertama yang dekat dengan kolam renang, titik kedua berada di atas area kolam dan titik ketiga. di atas dekat dengan daerah pendaratan paralayang.

Analisis Data wawancara pengunjung berdasarkan SWOT (Strength, Weakness, Opportunity, Threat).

\section{Analisis Faktor Internal}

\begin{tabular}{|c|c|c|c|}
\hline No. & Strength & & Faktor \\
\hline 1. & $\begin{array}{l}\text { Attraction } \\
\text { (Atraksi) }\end{array}$ & Wawancara & $\begin{array}{l}\text { - Berdasarkan hasil wawancara, yang dapat dikembangkan } \\
\text { adalah, kolam Renang mata air diperbesar, dengan sistem } \\
\text { pengairan dan pembuangan air diperbaiki, antara kolam } \\
\text { utama, murni hanya untuk penampuangan mata air, lalu } \\
\text { kolam renang anak - anak diperbaiki, supaya tidak kumuh } \\
\text { - } \quad \text { Panorama alam yang sejuk indah, yang dikelilingi oleh } \\
\text { hijaunya pegunungan Teh. } \\
\text { - Atraksi olah Raga Paralayang }\end{array}$ \\
\hline 2 & $\begin{array}{l}\text { Amenities } \\
\text { (Fasilitas) }\end{array}$ & Observasi & $\begin{array}{l}\text { - Mata air yang keluar dari tanah yang kolamnya di terai } \\
\text { ikan, namun tidak membuat airnya menjadi amis } \\
\text { - } \quad \text { Landingnya paralayang yang dijadikan aktrasi }\end{array}$ \\
\hline \multirow{3}{*}{3} & \multirow{3}{*}{$\begin{array}{l}\text { Accesibility } \\
\text { (Aksesibilitas) }\end{array}$} & Sapta Pesona & - Sejuk, Indah , tertib, kenangan dan aman \\
\hline & & Wawancara & $\begin{array}{ll}\text { - } & \text { Domisili alam masih sangat kental dibandingkan fasilitas } \\
\text { - } & \text { buatan yang didirikan di lokasi tersebut } \\
\text { - } & \text { Lahan parkir } \\
\text { - } & \text { Tempat pembuangan sumpah } \\
\text { - } & \text { Tempat Ibadah (Mushola) } \\
\text { - } & \text { Toilet } \\
\text { - } & \text { Penyawaan Ban dan tiker }\end{array}$ \\
\hline & & Observasi & $\begin{array}{l}\text { - Terdapat dua canopy yang tidak terawat } \\
\text { - } \quad \text { Terdapat tempat duduk yang terbuat dari bahan yang } \\
\text { terbaut dari bahan alami }\end{array}$ \\
\hline
\end{tabular}




\begin{tabular}{|c|c|c|c|}
\hline & & $\begin{array}{l}\text { Sapta Pesona } \\
\text { Wawancara } \\
\text { Observasi } \\
\text { Sapta Pesona }\end{array}$ & $\begin{array}{ll}\text { - } & \text { Aman } \\
\text { - } & \text { Mudah di jangkau dengan transportasi umum dan pribadi } \\
\text { - } & \text { Jarak antara jalan raya dan lokasi tidak jauh, masih dapat } \\
\text { ditempuh dengan jalan kaki } & \\
\text { - } & \text { Jalanannya masih sangat terjal bahaya untuk motor dan } \\
\text { memerlukan perbaikan } & \\
\text { - } & \text { Tertib, Aman }\end{array}$ \\
\hline No. & $\begin{array}{c}\text { Weaknesses } \\
\text { (Kelemahan) }\end{array}$ & & Faktor \\
\hline 1. & $\begin{array}{l}\text { Attraction } \\
\text { (Atraksi) }\end{array}$ & Wawancara & $\begin{array}{l}\text { - } \quad \text { Bangunan masih alami jadi rawan terhadap bencana alam } \\
\text { - Tidak terdapat penghalang antara mata air dan jalan setapak } \\
\text { Yang dilalui pengunjung dan juga kondisi area yang masih } \\
\text { terdapat sampah di beberapa sudut } \\
\text { - } \quad \text { Hygine dan sanitasi dari kolam tersebut belum ada yg } \\
\text { Memonitor } \\
\text { - } \quad \text { Cuaca yang sulit diprediksi, sering turun hujan } \\
\text { - Mata air nya adalah air dingin, dan tidak semua suka air } \\
\text { dingin }\end{array}$ \\
\hline 2. & $\begin{array}{l}\text { Amenities } \\
\text { (Fasilitas) }\end{array}$ & Observasi & $\begin{array}{l}\text { - Harus dikembangkan di sesuaikan dengan kemajuan jaman } \\
\text { Karena sudah banyak pesaing sepanjang menuju ke lokasi } \\
\text { - } \quad \text { Promosi yang masih kurang maksimal }\end{array}$ \\
\hline & & Sapta Pesona & $\begin{array}{l}\text { Keadaan dilokasi, masih terdapat sampah di beberapa sudut } \\
\text { Pengunjung masih kurang sadar akan pentingnya buang } \\
\text { Sampah pada tempatnya, }\end{array}$ \\
\hline 3. & $\begin{array}{l}\text { Accesibility } \\
\text { (Aksesibilitas) }\end{array}$ & Observasi & - Harus ada pengembangan dari mata air nya \\
\hline & & Wawancara & 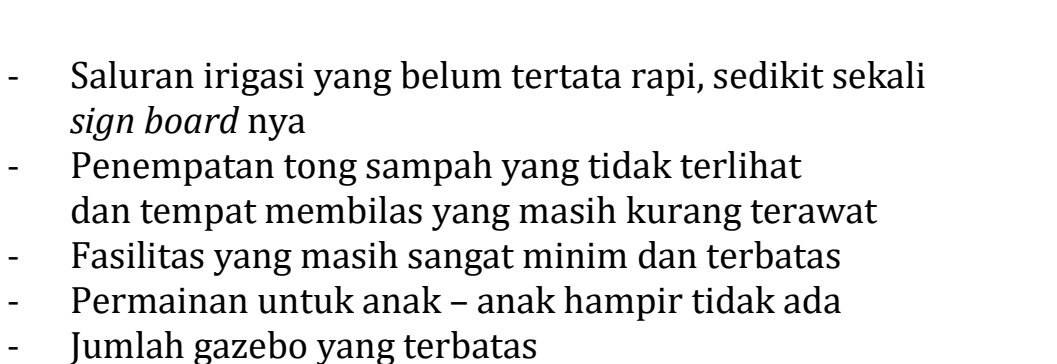 \\
\hline
\end{tabular}




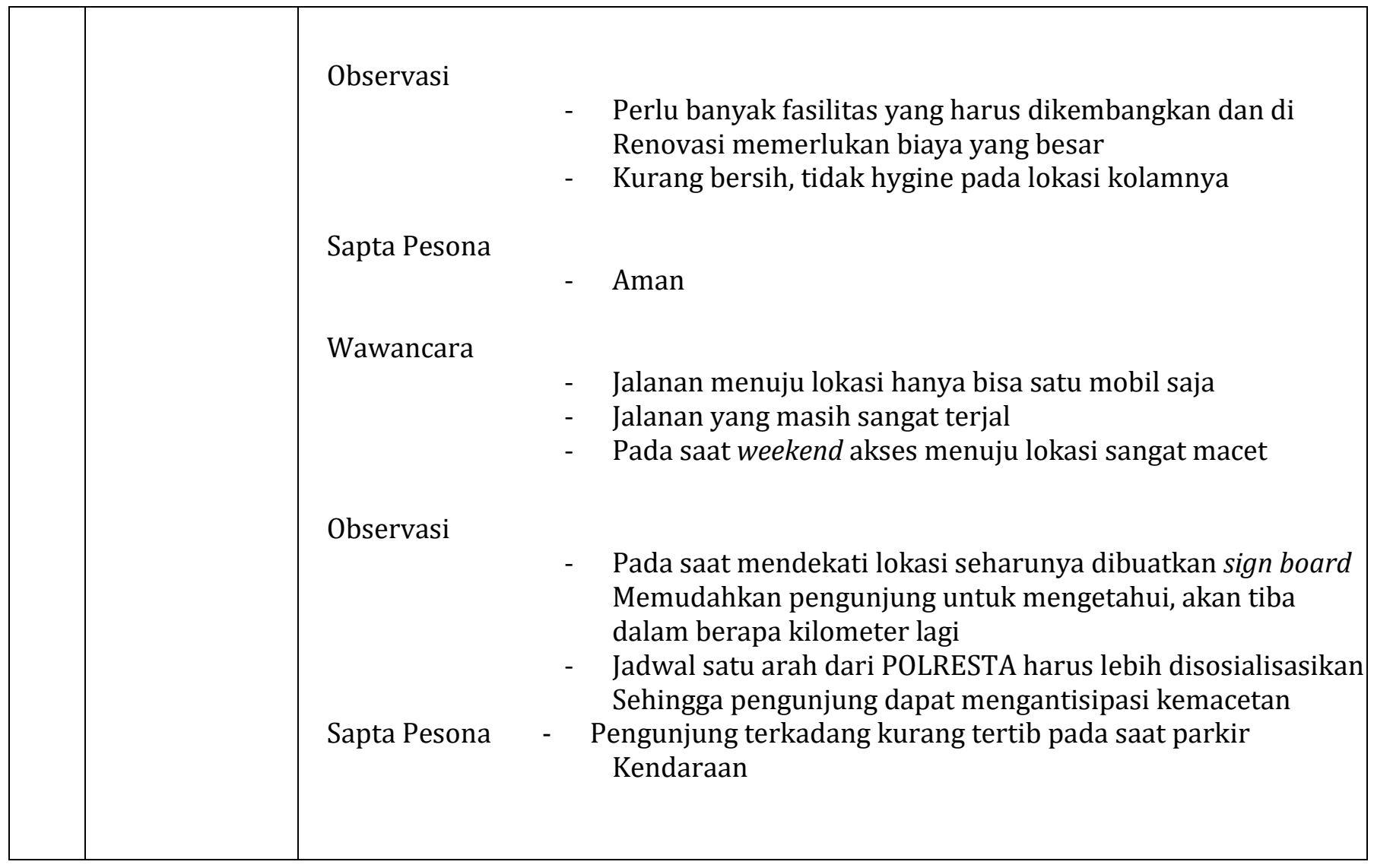

\section{Analisis Faktor Eksternal}

\begin{tabular}{|c|c|c|}
\hline No. & Opportunities (Peluang) & Dimensi \\
\hline $\begin{array}{l}2 . \\
3\end{array}$ & $\begin{array}{l}\text { Ekonomi } \\
\text { Politik } \\
\text { Sosial dan Budaya }\end{array}$ & $\begin{array}{l}\text { - Mata air Ciburial dikelola menjadi wisata kebugaran } \\
\text { akan menjadi sumber pendapatan. } \\
\text { - Mata air Ciburial di kelola oleh BUMN } \\
\text { - } \begin{array}{l}\text { Kesadaran akan pentingnya hidup sehat dan bugar } \\
\text { dengan cara memanfaatkan alam yang ada }\end{array}\end{array}$ \\
\hline No. & Threats (Ancaman) & Dimensi \\
\hline 1. & $\begin{array}{l}\text { Ekonomi } \\
\text { Politik }\end{array}$ & $\begin{array}{l}\text { a. Persaingan ketat dengan pengembangan wisata yang } \\
\text { sudah maju sekitar Gunung Mas khususnya mata air } \\
\text { Ciburial } \\
\text { a. Keadaan politik mempengaruhi keamanan dan kenyamanan } \\
\text { suatu wilavah. }\end{array}$ \\
\hline 4. & Sosial dan Budaya & $\begin{array}{l}\text { a. Pengaruh budaya luar yang dapat memberikan } \\
\text { dampak buruk terhadap tatanan sosial budaya lokal } \\
\text { yang terdapat di masyarakat Gunung Mas } \\
\text { a. Pesatnya kemajuan teknologi yang memposting daya } \\
\text { tarik sehingga mendatangkan wisatawan yang tidak }\end{array}$ \\
\hline
\end{tabular}




\begin{tabular}{|c|l|l|}
\hline 5. & Bencana Alam & kondusif \\
& $\begin{array}{l}\text { a. Curah hujan yang tinggi dan terjadi secara terus- } \\
\text { menerus sehingga berdampak keruhnya pada mata air } \\
\text { Ciburial }\end{array}$ \\
\hline
\end{tabular}

Analisis Matriks SWOT

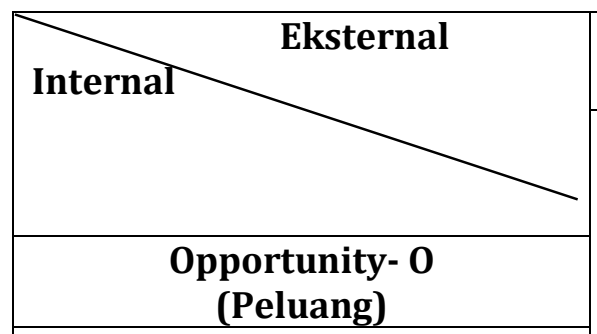

1. Mempunyai peluang bisnis Untuk wisata kebugaran (SPA)

2. Peluang usaha dikawasan mata air Ciburial

1. Dibuatkan fasilitas olah raga yang ramah lingkungan

2. Menyerap banyak tenaga kerja yang profesional

3. Mengubah gaya tren wisata menjadi wisata minat khusus

\begin{tabular}{|l|c|}
\hline \multicolumn{1}{|c|}{$\begin{array}{c}\text { Strength - S } \\
\text { (Kekuatan) }\end{array}$} \\
\hline $\begin{array}{l}\text { 1. Melestarikan daya tarik } \\
\text { wisata (mata air Ciburial) } \\
\text { yang potensial. }\end{array}$ \\
2. Mensinergikan potensi \\
daerah dengan kebijakan \\
pemerintah dan masyarakat \\
dalam pengembangan mata \\
air Ciburial
\end{tabular}

3. Atraksi olah raga Paralayang sebagai daya tarik wisata

4. Mengoptimalkan lahan yang cukup luas untuk pengembangan wisata kebugaran

5. Memudahkan aksesibilitas wisatawan untuk datang berkunjung

\section{Strategi S-0}

1. Mengooptimalkan potensi daya tarik wisata untuk memenuhi kebutuhan pasar dan peningkatan pendapatan masyaratkat dan pengelola

\section{Threats - T (Ancaman)}

1. Kemajuan teknologi yang berlebihan

2. Persaingan ketat dengan destinasi yang berada disekitar Gunung Mas

3. Bencana Alam

4. Kenyamanan dan keamanan masyarakat sekitar

5. Kerusakan lingkungan
2. Berkoordinasi dengan pihak pemerintah terhadap pengembangan SPA untuk wisata kebugaran

3. Sosialisasi manfaatnya olah raga paralayang bagi kesehatan

4. Ketersediaan aksessibilitas yang cukup memadai dengan konsep back to nature

5. Aksesibilitas dibuat mudah untuk pengunjung yang dengan cara sosialisasi sistem satu arah, dan jalan

\section{Weakness -W (Kelemahan)}

1. lemahnya kualitas SDM

2. Dikelola oleh BUMN

3. Promosi yang kurang maksimal dan termasuk kedalam olah raga yang mahal

4. Memerlukan dana yang cukup besar

5. Sarana dan prasarana serta fasilitas umum yang masih minim termasuk sign board yang terdapat di mata air Ciburial 


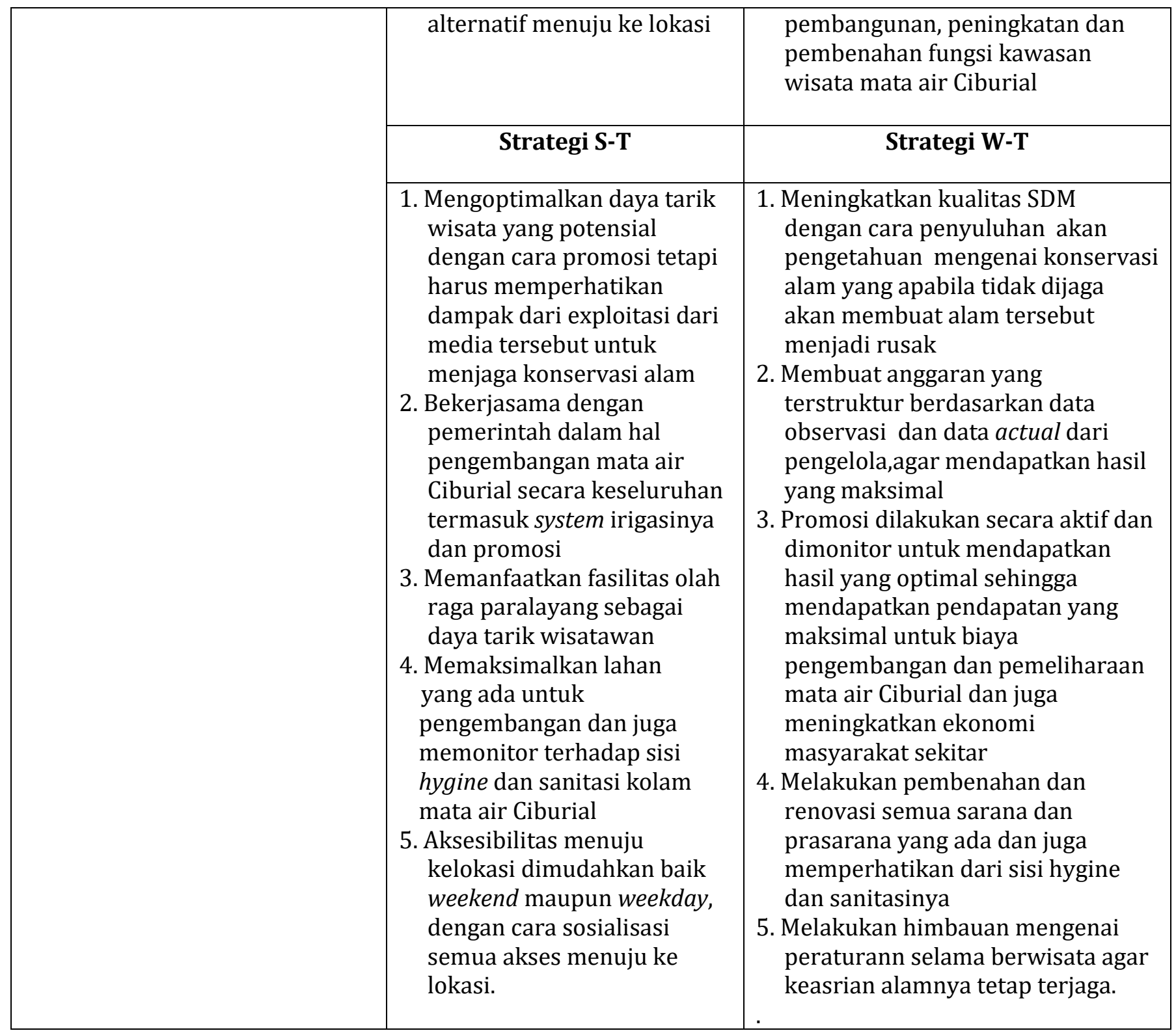

Setelah menyusun matrix SWOT terdapat beberapa strategi pengembangan mata air Ciburial yang dapat dijadikan rekomendasi kepada pihak pengelola. Strategi pengembangan mata air Ciburial yang dapat diterapkan dari hasil analisis SWOT meliputi:

a. Memanfaatkan daya tarik wisata mata air Ciburial untuk dikembangkan menjadi daya tarik wisata kebugaran, dengan konsep kesehatan dan kebugaran, dengan memanfaatkan sumber daya alam.

b. Dukungan kebijakan pemerintah daerah terkait pengembangan mata air Ciburial menjadi wisata kebugaran (SPA)

c. Meningkatkan kualitas SDM melalui pelatihan menjadi terapis yang professional, sehingga akan berbeda dengan SPA yang lainya, dann diharapkan dengan terapis yang terampil dapat menciptakan memorable 
experiance dan diharapkan untuk datang kembali.

d. Membuat skala prioritas untuk pengembangan daya tarik mata air Ciburial terkait pengaturan anggaran yang dibutuhkan, sehingga semua anggran yang dibuat tepat pada sasaran dan sesuai dengan apa yang dibutuhkan untuk pengembangan suatu destinasi wisata.

e. Kerja sama antara pemerintah dan masyarakat serta industri pariwisata dan juga pengelola SPA terkait pengembangan mata air Ciburial menjadi wisata kebugaran yang mengutamakan alam, sehinnga tidak keluar dari konsep awal yaitu memberdayakan sumberdaya alam yang ada, untuk meningkatkan pendapatan ekonomi baik pengelola maupun masyarakat sekitar.

a. Aksesibilitas

Asksesibilitas merupakan faktor yang sangat penting dalam suatu pengembangan daya tarik wisata mata air Ciburial. Aksesibilitas utama menuju mata air Ciburial sudah sesuai berdasarkan teori accessibility menurut Cooper (2000),

"Accessibility atau

aksesibilitas adalah sarana dan infrastruktur untuk menuju destinasi."Berdasarkan teori tersebut aksesibiltas merupak aspek yang sangat penting untuk mendatangkan wisata ke destinasi tersebut

Dan untuk saat ini akses menuju kelokasi dapat ditempuh dengan menggunakan berbagai macam alat transportasi, kendaraan roda dua, kendaraan roda empat, dan transportasi umum, angkutan umum dengan jurusan Cisarua - Bogor atau menggunakan Bus dengan tujuan ke Cipanas atau Cianjur dan yang terakhir dapat mengunakan L -300 angkutan khusus dari Bogor menuju ke Cianjur, jadi semua akses dapat digunakan, sesuai dengan kebutuhan. Dan untuk rumah sakit pun lokasinya tidak jauh dari mata air Ciburial

\section{b. Amenities}

Amenitas yang ada di mata air Ciburial sesuai dengan teori Cooper (2000),

"Amenity atau amenitas adalah segala fasilitas pendukung yang bisa memenuhi kebutuhan dan keinginan wisatawan selama berada di destinasi wisata." Berdasarkan teori tersebut, amenitas merupakan penunjang utama untuk wisatawan agar mendapatkan pelayanan yang sesuai pada saat berwisata.

Berikut adalah beberapa fasilitas yang ada di mata air Ciburial yaitu tempat parkir, pondopo, canopy, toilet umum, sign board, Post informasi, Pos keamanan dan tempat untuk membasuh setelah berenang.dan juga tempat Ibadah yang harus di perbaiki untuk menunjang pengembangan Mata air Ciburial.

\section{c. Attraction}

Potensi wisata yang dapat dikembangkan di Mata air Ciburial, mata air itu sendiri, khasiat dari kandungan air yang berasal dari mata air sangat baik untuk kesehatan dan 
kebugaran, panorama alam yang hijau dan sejuk ditambah dengan aktraksi olah raga paralayang. Dapat dikembangkan menjadi wisata kebugaran posisinya berada di tengah alam dan akan menjadi satu - satunya SPA yang lokasinya berada di alam langsung, sehingga efek dari kebugaranya akan langsung dirasakan, selama treatment sampai dengan selesai. Dan juga penggunaan dari produk teh untuk bahan SPA yaitu dapat digunakan untuk scrab atau untuk lulur dan juga dapat dikonsumsi sebagai salah satu minuman herbal yang bagus untuk kesehatan, terutama teh hijau.

Atraksi wisata tersebut sudah sesuai dengan teori attraction berdasarkan Cooper (2000),

"Attraction atau atraksi adalah produk utama sebuah destinasi. Atraksi berkaitan dengan what to see dan what to do. Apa yang bisa dilihat dan dilakukan oleh wisatawan di destinasi tersebut. Atraksi bisa berupa keindahan dan keunikan alam, budaya masyarakat setempat, peninggalan bangunan bersejarah, serta atraksi buatan seperti sarana permainan dan hiburan."

Berdasarkan teori tersebut, atraksi merupakan tempat wisata yang didalamnya terdapat sesuatu yang unik sehingga menarik perhatian pengunjung

\section{SIMPULAN}

Merujuk pada hasil penelitian diperoleh informasi bahwa: (1) Kedatangan turis yang rendah karena, tidak dapat bersaing dengan tempat wisata lainnya yang berdekatan dengan Gunung Mas, Monoton hanya melihat pemandangan alam saja, sarana dan prasarana yang minim, akses ke lokasi selalu terpapar satu arah (buka puncak jalur atas); (2) Mata air Ciburial dapat dimanfaatkan sebagai obyek wisata keboragan, karena memiliki unsur unsur yang dibutuhkan oleh SPA itu sendiri, yaitu keindahan alam yang dapat memberikan kesejukan dan ketenangan jiwa, mata air keluar dari tanah yang memberi efek. kesegaran dan teh yang bisa dikonsumsi untuk minuman herbal dan juga untuk bahan SPA, dan; (3) Dari hasil analisis SWOT dapat digambarkan sebagai berikut: Hasil analisis internal mata air Ciburial, yaitu kekuatan Agrowisata Gunung Mas, khususnya mata air Ciburial, berpotensi untuk dikembangkan menjadi wisata kesehatan, mata air yang keluar dari tanah yang mengandung khasiat bagi kesehatan dan tubuh dapat membuat tubuh menjadi lebih bugar dan didukung oleh pemandangan alam yang indah dari teh hijau. Pegunungan yang bisa mendinginkan mata dan juga ditambah dengan produk teh yang bisa digunakan untuk minuman herbal, dan ditambah dengan pengunjung bisa melihat atraksi olahraga paralayang.

- Hasil analisis internal pegas Ciburial, yaitu kelemahan Kelemahan sumber daya manusia yang dimiliki Gunung Mas, dan agro Gunung Mas berada di bawah badan usaha milik negara, sehingga dalam perkembangannya akan membutuhkan birokrasi yang cukup lama, yang dapat dikembangkan selain mata air atraksi wisata paralayang dan olahraga ini meliputi Menjadi 
olahraga yang mahal, jadi tidak semua orang bisa melakukannya, dan dalam pengembangan mata air Ciburial ini membutuhkan dana yang banyak untuk memperbaiki semua sarana dan prasarana yang ada.

- Hasil analisis eksternal mata air Ciburial, yaitu peluang Wisata Agro Gunung Mas, khususnya mata air Ciburial berpotensi untuk dikembangkan menjadi wisata kesehatan, sekaligus membuka peluang bisnis untuk meningkatkan pendapatan dan masyarakat sekitar. Dengan adanya peningkatan fasilitas yang menunjang wisata kesehatan, sehingga dapat mengubah kecenderungan pariwisata massal yang awalnya menjadi wisata minat khusus, dan ini sangat baik untuk pembangunan yang mengandalkan potensi alam, sehingga alam tidak terpapar secara berlebihan agar tetap terjaga.

- Hasil analisis eksternal terhadap mata air Ciburial, adalah ancaman meningkatnya jumlah pesaing yang berada di sekitar Gunung Mas, implaksi harus memaksimalkan promosi, harus lebih agresif lagi, karena lokasinya terbuka sehingga mengetahui cuaca atau keadaan alam sangat penting.

- Pengembangan strategi wisata Gunung Mas Agro, mata air Ciburial dapat dijabarkan dari strategi masing-masing kotak pada matriks SWOT dengan pengembangan esensi yang menekankan pengembangan terstruktur dengan mengembangkan mata air Ciburial yang berada di Gunung Mas menjadi sebuah wisata kebugaran atau dapat menjadi disebut wisata kesehatan, dengan memanfaatkan potensi alam yang adalah

\section{DAFTAR PUSTAKA}

Barre, K., et al. (2005). A Feasibility Study for a Yukon Pariwisata health and Wellness Industry. North to Knowledge, Learning Travel Product Club, and The Department of Tourism and Culture. Yukon Territorial Government.

Cooper, C. et al. (2005). Tourism Principle and Practice edisi ketiga. Harlow: Pearson Education Limitted.

Cooper, C., et al.(2000). Tourism: Principle and Practice, edisi kedua, dalam Shepherd, R.(Ed) (2003), dalam Govers, R \& Go, F. (2009). Place Branding: Glocal, Virtual, and physical identities, Constructed, Imagined and Experienced. London: Palgrove Macmillan, hal.67.

Drum, \& Moore, A. (2005). An Introduction to Ecotourism Planning. Second Edition. Virginia: Nature Conservancy Arlington, hal 15

Darmaji, R.S. (2001). Istilah - Istilah Dunia Pariwisata. Jakarta: PT. Pradnya.

Kotler, B., \& James, C. (2009). Marketing for Hospitality and Tourism.

Kotler, P. (2011). Manajemen Pemasaran di Indonesia: Analisa, Perencanaan, Implementasi dan Pengendalian. Jakarta: Penerbit Salemba Empat

Middleton, V.T.C.(2001). Marketing in Travel and Tourism. $3^{\text {rd }}$ Edition. MPG Books Ltd, Bodmin.

Peter R.Y., Pasla., \& Dinata, D.I.S.(2004). Persepsi Masyarakat Surabaya Terhadap Spa Sebagai Sarana Perawatan Kesehatan, Kebugaran Dan Kecantikan. Vol.6, No. 1, Edisi Maret 2004, 82-92 
Pramono, J. (2013). Strategi Pengembangan Health and Wellness di Bali. Jurnal Manajemen. Strategi Bisnis dan Kewirausahaan Vol.7,No.1 Edisi Februari 2013, 68

Pendit, N.S. (2002). Ilmu Pariwisata Sebuah Pengantar. Jakarta: Pradnya

Rogayah, L.D. (2007). Pariwisata Kesehatan Di Jawa Barat, Retrieved on 02 november 2009 from http://irdanasputra.com/2009 /11/pariwisata

Ross, K. (2001). "Health Pariwisata: An overview." HSMAI Marketing Review, (December). Downloaded from: www.hospatality/net.org

Romula, et. al. (2007). Strategi Pengembangan Health and Wellness Di Bali. Jurnal Manajemen,Strategi Bisnis dan Kewirausahaan Vol.7,No.1 Edisi Februari 2013, 67.
Undang - undang RI nomor 10 tahun 2009 tentang kepariwisataan

Yoeti, O.A.(2002). Perencanaaan Strategis Pemasaran Daerah Tujuan Wisata. Jakarta: Pradnya Paramitha.

\section{UCAPAN TERIMA KASIH}

Peneliti mengucapkan banyak terima kasih kepada pimpinan Sekolah Tinggi Pariwisata Bogor, Agrowisata Gunung Mas atau PT Perkebunan VIII, sebagai tempat peneliti untuk melakukan penelitian selama ini, kepada Dosen Pembimbing Prof. Dr. Ir. Sugiarto, M.Sc dan Bapak Hengki Hermantoro dan dosen Penguji Pasca Sarjana Sekolah Tinggi Pariwisata TRISAKTI, dan juga kepada semua pihak yang terkait dalam penelitian ini yaitu narasumber karyawan yang bekerja di Agrowisata Gunung Mas khususnya Mata Air Ciburial. 